
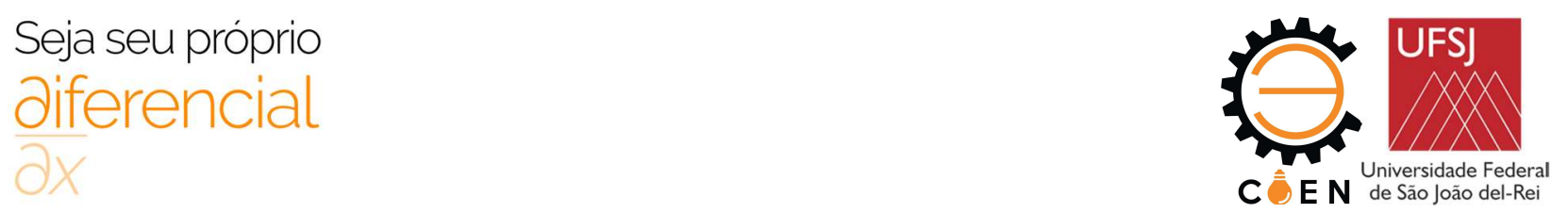

\title{
AVALIAÇÃO DE DESEMPENHO APLICADA A UMA EQUIPE DE FÓRMULA SAE
}

\author{
Carla Fabiana Silva Nery ${ }^{(1)}$ (carlafsnery@gmail.com), Lucas Apolonio de Almeida Martins ${ }^{(1)}$ \\ (lucas_apolonio1322@hotmail.com), Victor Thomaz da Cunha Aragão ${ }^{(1)}$ (victoraragao67@gmail.com) \\ ${ }^{(1)}$ Universidade Federal de São João del-Rei (UFSJ) - Departamento de Engenharia Mecânica-Pç Frei Orlando, 170, Centro, São João \\ del-Rei
}

RESUMO: Em um mundo altamente globalizado como o atual, as pessoas são consideradas a cada momento fatores mais preponderantes para o sucesso das organizações, visto que, são elas que fortalecem a imaginação, criatividade, inovação e dinâmica das instituições. Em razão disso, a gestão de pessoas $e$ avaliação de desempenho humano tem se tornado cada vez mais presente nas empresas. Por isso, a área busca o desenvolvimento, retenção e motivação do trabalhador para o desempenho de suas funções e tarefas. Nesse sentido, o artigo em questão busca analisar como a Avaliação de Desempenho, área da Gestão de Pessoas, é praticada na equipe Fórmula Del-Racing UFSJ, e como a área corrobora na manutenção dos integrantes, alinhados ao aumento de motivação e capacitação dos membros, além de demonstrar a crescente evolução da equipe no cenário nacional. Sendo assim, através do estudo de caso na equipe de Fórmula SAE da cidade de São João Del-Rei - MG foi possivel a verificação e análise da avaliação $360^{\circ}$, que através de cinco competências relacionadas em escalas numéricas e textuais, desenvolve gráficos e feedbacks em um sistema integrado entre todos os setores e membros da organização. Com o intuito geral de demonstrar a importância desse quesito para a corporação e de que forma a aplicação dessa ferramenta vem contribuindo desde sua implementação no desenvolvimento da equipe, o artigo passa por pontos fundamentais tanto da história e base teórica da avaliação de desempenho e gestão de pessoas, tal como o relacionamento do integrante no âmbito estudantil e profissional.

PALAVRAS-CHAVE: Gestão de pessoas, avaliação de desempenho, avaliação $360^{\circ}$, feedback, fórmula.

\section{INTRODUÇÃO}

Durante décadas, organizações preocuparam-se exclusivamente com a eficiência mecânica como forma de maximização dos objetivos, entretanto, tais investimentos não resultavam no esperado. Diante disso, com o passar dos anos, observou-se que a ação humana é responsável pela dinâmica e vida da organização. Nesse contexto, viu-se a necessidade do reconhecimento dos recursos humanos (RH), que quando bem-sucedido, pode gerar o crescimento e desenvolvimento das organizações, ou no mínimo, sua sobrevivência. Além disso, o RH assume um papel estratégico dentro das organizações, de forma que passe a ser a competência básica da instituição, garantindo vantagens em um mundo globalizado e fortemente competitivo. Em 1920, o principal foco da gestão de recursos humanos nas instituições era especificamente realizar a parte burocrática da contratação. Segundo Monteiro et al. $(2015$, p. 3):

Grandes empresas motivadas a compreender a relação entre suas organizações e trabalhadores decidiram patrocinar estudos relacionados ao tema. Na década de 20, observa-se o surgimento do movimento de relações humanas, atrelado a um novo conceito, no qual o relacionamento entre empregados e empregadores já apresentavam sinais de desencontro de interesses.

Somente na década de 50 o comportamento humano do funcionário passou a ser avaliado, tão quanto a sua prestação de serviço. Dessa forma, o trabalhador que antes era visto apenas como mão de obra, que só tinha serventia de emprestar seu serviço para o desenvolvimento diário em uma empresa

IX COEN - Congresso de Engenharias da UFSJ Interconexão. 

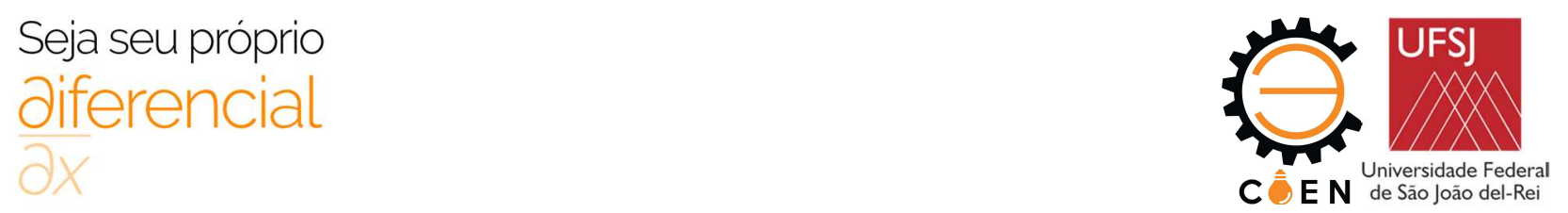

qualquer, num lugar qualquer, era para muitos apenas extensões das máquinas (BOWDITCH; BUONO, 2002). Entretanto, atualmente observa-se que o trabalhador possui uma atuação mais complexa, e este reconhecimento ultrapassa a área dos recursos humanos. Nesse âmbito, tem-se a percepção que o trabalhador é um ser pensante, com sonhos, desejos e expectativas dotado de inteligência e vontade.

Segundo Chiavenato (2014), as pessoas se transformaram em elementos importantes para o sucesso das empresas, pois passaram de meros empregados à colaboradores de voz ativa. De fato, junto a essa transformação vieram a valorização, os incentivos e treinamentos para preservarem talentos que progredissem em conjunto com os objetivos da empresa. A partir disso, observa-se que tratar as pessoas como recursos organizacionais e julgar as pessoas como patrimônio físico da instituição é um desperdício de talento e, por isso, hoje fala-se em Gestão de Pessoas (GP) e não mais em recursos humanos, exatamente para proporcionar essa nova visão: tratar os membros como parceiros, afirma Chiavenato (2014).

Nessa perspectiva, surge o conceito de Avaliação de Desempenho (AD), termo inserido na grande área da GP, que busca a comparação entre resultados efetivos e esperados do trabalho de algum indivíduo ou organização. Além disso, a AD oferece para a organização uma ferramenta gerencial que possibilita conduzir a gestão de desempenho de forma mais eficaz. Tais ferramentas buscam a motivação, qualidade, produtividade e resultados positivos de trabalho, sendo esses objetivos alcançados a partir de diversas metodologias de aplicação com grande variabilidade entre as empresas.

Com base nesses fundamentos, notou-se que é de suma importância a aplicação da metodologia Avaliação de Desempenho sobre os universitários integrantes da equipe de competição Fórmula DelRacing UFSJ. A equipe em questão teve início em 2011 e atualmente possui 50 integrantes das áreas de Engenharia Elétrica, Mecânica e de Produção da Universidade Federal de São João del-Rei, subdivididos em nove setores. A equipe compõe a categoria Fórmula SAE Brasil que objetiva o desenvolvimento de um protótipo estilo Fórmula para a participação em competições organizadas pela SAE - Society of Automotive Engineers.

A aplicabilidade da ferramenta tem como visão analisar o desempenho dos colaboradores e possibilitar retroação de seus comportamentos, o que a torna fundamental para a gestão estratégica de pessoas. Visto isto, desde meados de 2017, notou-se a necessidade da criação do subsetor de Gestão de Pessoas e consequentemente a aplicação periódica da avaliação de desempenho. Nessa linha, dentre as metodologias da ferramenta, a equipe baseia-se na Avaliação $360^{\circ}$ pela possibilidade de gerar uma qualidade de informação melhor já que é formada por múltiplas perspectivas. A denominação $360^{\circ}$ está relacionada ao fato de que um mesmo colaborador é avaliado por todos ou quase todos os integrantes de seu ciclo, o que possibilita o maior número de informações para a identificação de melhoria no desempenho do colaborador.

Portanto, a metodologia de pesquisa caracteriza-se como exploratória de natureza aplicada e método qualitativo. Dessa maneira, o artigo em questão consiste em um estudo de caso, sendo estruturado em cinco seções, sendo a primeira a introdução. Na seção 2 são considerados os principais objetivos do estudo, de forma a analisar como a avaliação contribui para o crescimento da equipe. A seguir, na seção 3, é relatado o referencial teórico de forma a abordar pontos como Gestão de Pessoas, Avaliação de Desempenho e Avaliação $360^{\circ}$. Na seção 4, são detalhados os Materiais e Métodos do estudo de caso. Por fim, na última seção são apresentadas as considerações finais, com os resultados e conclusões.

\section{OBJETIVOS}

O principal objetivo deste estudo é apresentar como a aplicabilidade da Avaliação deDesempenho interfere na performance do integrante da equipe Fórmula Del-Racing UFSJ, de 

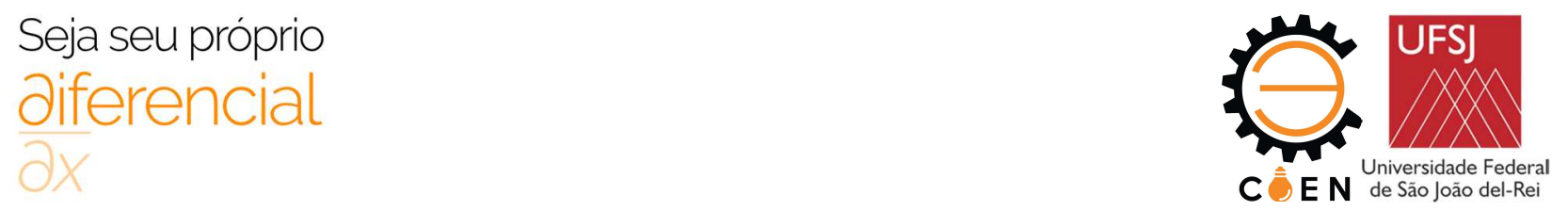

forma a relacionar a influência no desenvolvimento coletivo da equipe. Além disso, permite ao avaliado reconhecer os pontos positivos e falhos, através do conhecimento e comparação de resultados em períodos distintos, a fim de relacioná-los ao desenvolvimento pessoal e profissional do integrante na vida acadêmica. Nessa linha, o estudo busca demonstrar a relação direta entre a avaliação de desempenho aplicada e o tempo de permanência dos integrantes na equipe.

Portanto, o estudo tem a finalidade de enfatizar o crescimento interpessoal e reconhecimento comportamental gerados aos integrantes através do feedback. Dessa forma, busca salientar como a Avaliação de Desempenho tornou-se um instrumento essencial e de influência para a Gestão de Pessoas da equipe. Por fim, a pesquisa fundamenta-se em conhecer a base teórica da Avaliação de Desempenho $360^{\circ}$ e evidenciar as melhorias para o avaliado desde o início de sua aplicação.

\section{REFERENCIAL TEÓRICO}

\subsection{Gestão de Pessoas}

De acordo com Chiavenato (2014), o contexto geral da gestão de pessoas é a formação da total interdependência entre pessoas e organizações, sendo que ambas as partes dependem uma da outra em um sistema de mútuo benefícios. Por isso, considera-se a GP como uma área de sensibilidade à cultura corporativa que há nas organizações.

Para Chiavenato (2014), a GP tem a finalidade de cooperar na eficácia organizacional de maneira a contribuir na conquista de seus objetivos, além de proporcionar à organização pessoas bem treinadas e motivadas. Desse modo, esse fator promove o aumento da satisfação dos funcionários e gera maior competitividade no mercado. Além disso, a gestão de pessoas busca a elevação e desenvolvimento da qualidade de vida no trabalho, tal como a administração e impulsionamento da mudança e da preservação de políticas éticas e de comportamentos socialmente responsáveis. Nessa linha, para que tais parâmetros sejam atingidos, a GP funciona através de um integrado processo dinâmico e interativo, intimamente relacionado entre si.

\subsection{Avaliação de Desempenho}

Os progressos existentes nas últimas décadas possibilitaram que as empresas buscassem novos meios de gestão com o objetivo de melhorar o desempenho, obter resultados, alcançar a missão institucional e entender as necessidades dos clientes. A partir disso, foi possível concluir que o sucesso das companhias está relacionado com os investimentos nas pessoas, isto é, elas são fatores essenciais que compõem a organização e garantem o alcance de vantagens competitivas no mercado (BARBOSA E ESTENDER, 2014).

Neste sentido, Matos (2012) aponta que a avaliação de desempenho, além de motivar, guiar e desenvolver as pessoas, tem como fundamento integrá-las para melhorar os resultados e alcançar os objetivos organizacionais, sendo então, uma ferramenta essencial na gestão dos recursos humanos.

Sendo assim, de acordo com o Sebrae, a avaliação de desempenho é um instrumento que analisa e reconhece as competências do colaborador, promovendo amadurecimento profissional e aperfeiçoando as habilidades, e para isso, é necessário que o mesmo tenha conhecimento da regularização da avaliação existente e a empresa deve obter uma retroação transcrita a partir de observações, resultados e conclusões do avaliador.

Por outro lado, para Borsatto (2012):

IX COEN - Congresso de Engenharias da UFSJ Interconexão. 

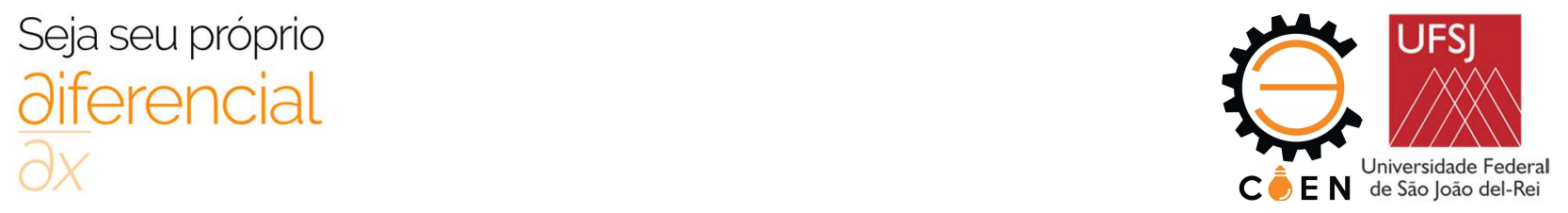

A avaliação de desempenho inicia com o planejamento estratégico, definição das metas, combinação dos resultados esperados pela equipe detrabalho, acompanhamento do processo e avaliação dos resultados conquistados. Possibilita que as equipes repensem constantemente seus processos de trabalho, com vistas ao aprimoramento (p. 22).

\subsection{Avaliação 360}

Segundo Chiavenato (2014), a avaliação $360^{\circ}$ é um processo em que cada colaborador além de realizar uma autoavaliação, é avaliado pelas principais pessoas que trabalham com ele, incluindo seu gerente ou superior direto, seus colegas de trabalho do mesmo nível e seus subordinados. Sendo assim, é uma forma mais rica de avaliação por fornecer diferentes informações, possibilitando que o colaborador se adapte e se ajuste a diferentes demandas que recebe em seu contexto de trabalho.

$\mathrm{O}$ modelo de avaliação $360^{\circ}$ requer da equipe maturidade e conhecimento da ferramenta, pois caso contrário pode gerar conflitos de várias ordens e natureza. Godoy (2007) afirma sobre o tema que:

A avaliação $360^{\circ}$ pressupõe sua aplicabilidade em empresas compostas por equipes maduras, em que as relações sejam transparentes, haja boa comunicação e se tenha em vista os objetivos estratégicos, por excelência. Em suma, relações profissionais que proporcionem o desenvolvimento das pessoas atrelado ao planejamento estratégico, porque nem todo contexto empresarial está preparado para sua implementação (p.48).

Nesse modelo de avaliação, o indivíduo, assim como nos métodos tradicionais, também faz sua autoavaliação. É preciso estar consciente do seu desenvolvimento e objetivos para não se auto avaliar de forma desarrazoada provocando desvios e mapeamentos opostos à realidade.

Brandão (2008) declara que:

A avaliação realizada por diversos atores é mais rica e fidedigna do que aquela feita por uma única pessoa, sobretudo porque os envolvidos passam a compartilhar a responsabilidade pelo processo e eventuais distorções na percepção de um dos avaliadores se diluem nas avaliações realizadas pelos demais (p. 883).

A utilização do modelo de avaliação $360^{\circ}$ requer da equipe conhecimentos e diálogo a fim de que a ferramenta avaliativa possa atingir os objetivos perseguidos. Assim, a ferramenta ganha importância quando na equipe se faz necessário a consideração de qualidades e pontos que devem ser mudados em relação a atitudes dos membros.

\section{MATERIAIS E MÉTODOS}

A pesquisa em questão consiste em um estudo de caso. Em virtude disso, parâmetros e competências não devem ser generalizados para outros âmbitos, visto a adequação para a realidade da equipe no meio universitário.

O estudo de caso a seguir é desenvolvido a partir do funcionamento da Avaliação de Desempenho na equipe em questão, e diante disso, segundo Segatto-Mendes e Mendes (2018):

IX COEN - Congresso de Engenharias da UFSJ Interconexão. 

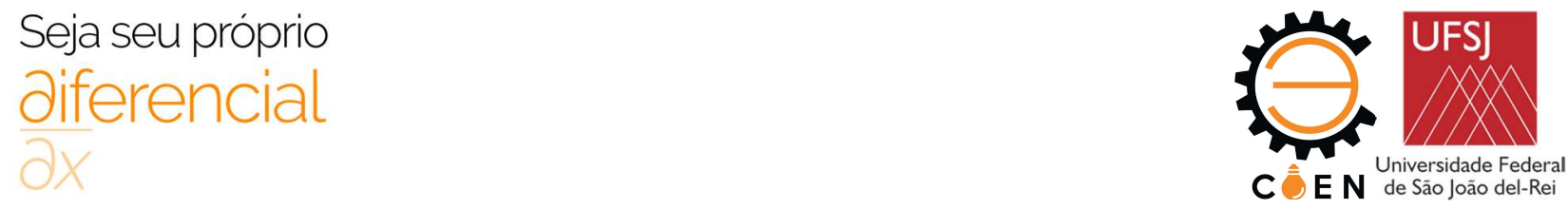

O estudo de caso é um método em que o fenômeno é estudado e analisado em seu contexto real, buscando avaliar as decisões que foram tomadas, o porquê de determinadas atitudes adotadas e em que resultaram. Desse modo, as causas e consequências do fenômeno e seu desenvolvimento vão sendo esclarecidos, sempre dentro do momento e circunstâncias em que ocorreram (p. 62).

$\mathrm{Na}$ equipe estudada, o objetivo da avaliação de desempenho está relacionado à necessidade de retroação a respeito do desenvolvimento por parte do integrante. Este processo auxilia na construção de feedbacks aos membros sobre seu desempenho e resultados obtidos. Consequentemente, a $\mathrm{AD}$ proporciona o julgamento sistemático de inúmeros fatores, podendo ocasionar em recomendação, advertência e/ou demissão. Além disso, possibilita ao membro a percepção de seus pontos fortes, os quais poderão ser utilizados em favor da equipe, e de seus pontos falhos, que precisam de atenção e melhoria.

Neste mesmo âmbito, Lamperti e Dewes (2016) apontam que o reconhecimento do funcionário por meio do feedback é de suma importância, visto que o retorno dado ao colaborador após ser avaliado auxilia no comportamento dos integrantes, seja para manutenção ou melhorias, permitindo ainda a orientação para novos comportamentos de acordo com cada indivíduo.

O processo aplicado na Equipe Fórmula Del-Racing UFSJ baseia-se na Avalição $360^{\circ}$, sendo o ciclo composto pela capitania (capitão e vice capitão), coordenador e membros do setor, como mostra na Figura 1. A capitania avalia todos os integrantes da equipe, enquanto o coordenador e os demais membros avaliam seu setor específico e a capitania, além disso, todos os integrantes se auto avaliam. Este processo é realizado quatro vezes ao ano, em busca de um acompanhamento mais detalhado e completo ao longo dos períodos do ano, de maneira distinta.

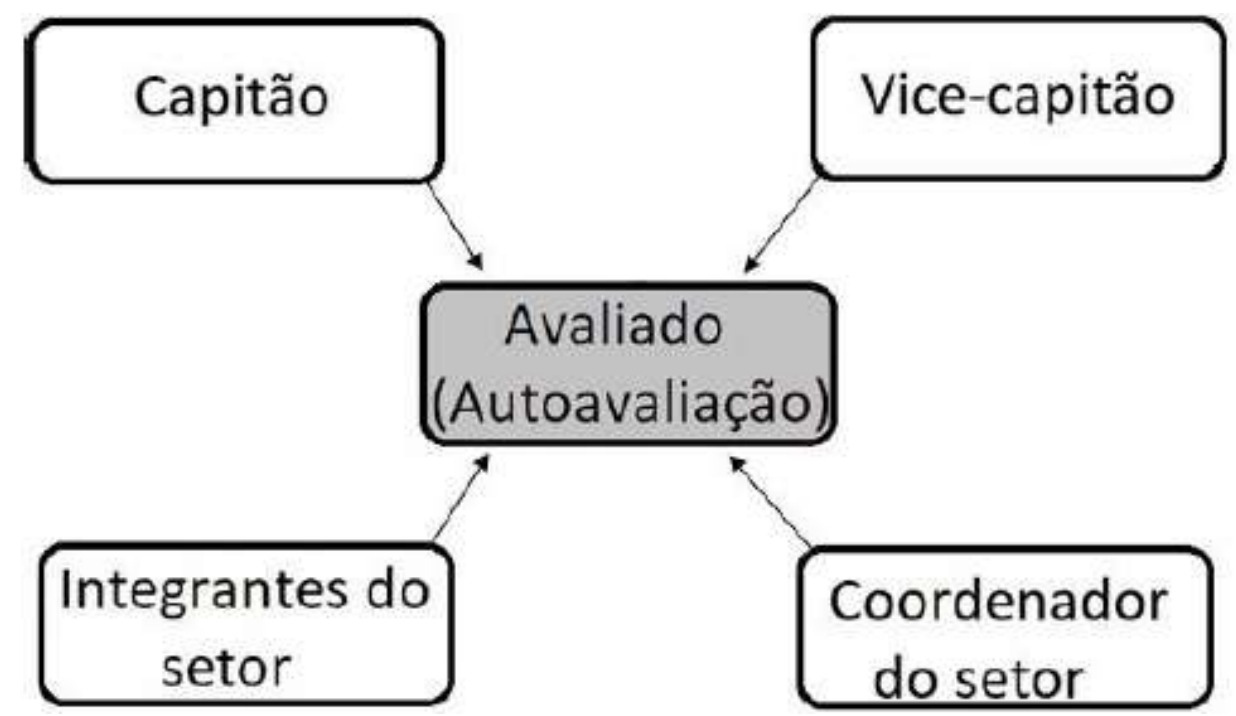

Figura 1. Modelo de Avaliação $360^{\circ}$ utilizado na equipe.

A Avaliação de Desempenho é realizada através de um questionário desenvolvido no Google Docs (formulário online) e consta com uma pontuação de 1 a 4 em cada competência. A escolha numérica se dá ao fato da busca pela neutralização da subjetividade e redução de interferências em

IX COEN - Congresso de Engenharias da UFSJ Interconexão. 
virtude dos pré-julgamentos que possam vir a ocorrer nas escolhas de parâmetros - ruim, intermediário, bom e excelente.

Além disso, a escala par, justifica-se com intuito de minimizar a tendência central comprovada em escalas ímpares. Isso é, com a escala ímpar, avaliadores tendem a atribuir notas centrais para não vir a prejudicar com notas reduzidas ou supervalorizar o avaliado com notas elevadas.

Nessa linha, ao ser disponibilizado, os membros têm 96 horas para preencher o formulário. Em cada tópico preenchido, é necessário que cada nota atribuída seja justificada. Através dessas justificativas, o subsetor da Gestão de Pessoas, que está inserido no setor da Engenharia do Produto, o responsável por filtrar os pontos relevantes e elaborar os comentários em forma de feedbacks para os demais membros, e em sequência, é marcado um horário individual com cada um dos membros para que sejam repassados. Ademais, é disponibilizado aos membros um gráfico que englobam os resultados obtidos na avaliação anterior, na avaliação atual e na autoavaliação, e um gráfico comparativo com os demais integrantes da equipe.

\subsection{Competências da Avaliação de Desempenho}

Identificam-se, na equipe, para um desempenho satisfatório dos integrantes, as seguintes competências: comprometimento, convivência, disponibilidade, interesse e presença. A seguir, são expostas as competências com maior detalhamento. Entretanto, vale ressaltar que definir a competência está distinto de definir tudo aquilo que o integrante faz, e sim, relacionar as capacitações que devem ser fomentadas, protegidas ou diminuídas. Na Figura 2, exemplifica-se uma das competências avaliadas.

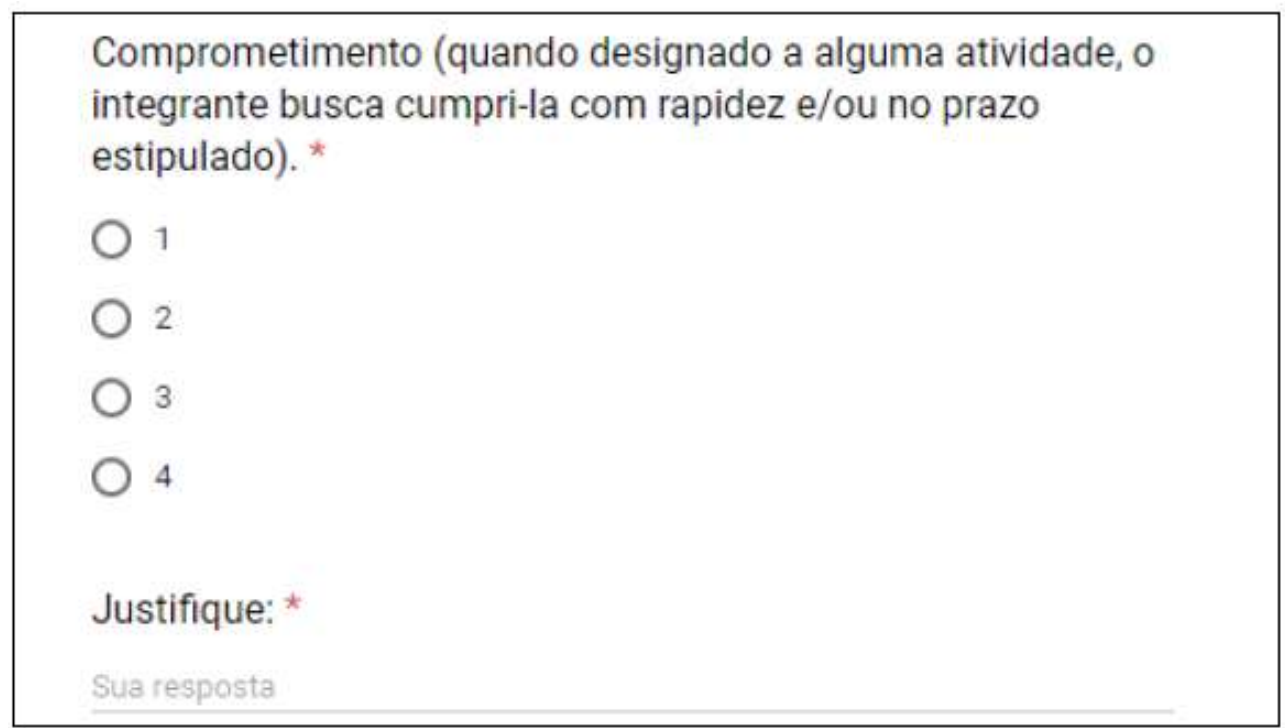

Figura 2. Modelo a ser preenchido na competência Comprometimento.

\subsubsection{Comprometimento}

A primeira competência é relacionada ao comprometimento. Ser comprometido no trabalho é muito mais que cumprir sua carga horária e realizar suas atividades. Significa assumir postura e atitudes favoráveis para o crescimento da instituição. Trata- se de estar verdadeiramente envolvido, 

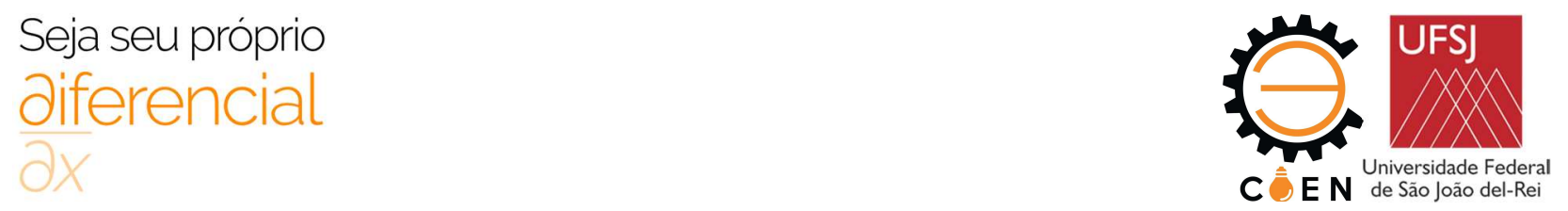

sendo ativo e participativo com os projetos, propondo possibilidades de melhoria e aumento de resultados e, principalmente, tomando ações concisas com as metas e objetivos almejados.

\subsubsection{Convivência}

A qualidade das relações dentro das organizações influencia diretamente na saúde física, mental e emocional do ser humano, consequentemente, a convivência possui relação total com o desenvolvimento da equipe. Por isso, é de fundamental importância para a aquisição de uma série de benefícios à preservação de um bom relacionamento no ambiente institucional para a manutenção de um clima saudável, prazeroso e motivador. Sendo assim, é importante a convicção nas atitudes para que haja o diálogo e não ocorra a perda da razão, visto que conflitos e opiniões divergentes são inevitáveis. Assim, com o aperfeiçoamento da capacidade de conversação e comunicação no trabalho, situações de estresse tendem a ser solucionadas de forma antecipada, sem maiores prejuízos.

\subsubsection{Disponibilidade}

A competência disponibilidade normalmente é atribuída para indicar o tempo que determinada pessoa apresenta para execução de qualquer tipo de tarefa que lhe for atribuída. $\mathrm{Na}$ equipe em pauta, pelo protótipo ser produzido de forma manual, são recorrentes problemas inesperados. Com isso, torna-se necessário que o integrante esteja disponível para a realização de tarefas extras do setor/equipe, seja em horários pós aula, finais de semana, feriados ou férias.

\subsubsection{Interesse}

Pelo ramo em que a equipe está inserida, é de fundamental importância por parte do integrante estar constantemente atento a novas tendências, além de buscar constantemente inovações para o setor e consequentemente para a equipe. Além disso, espera-se em interesse, que o membro procure novos conhecimentos para melhorar o seu desempenho individual e da produtividade da equipe.

\subsubsection{Presença}

A presença nas instalações da equipe é fundamental para troca mútua de conhecimento entre os integrantes. Por isso, esse quesito está relacionado à participação frequente do avaliado nas atividades e dependências da equipe, além do cumprimento dos horários estipulados.

\subsection{Tratamento dos dados}

Através das notas atribuídas na avaliação, com auxílio do Software Excel, são gerados quatro gráficos para análise comportamental do avaliado e da equipe. Os gráficos são repassados em conjunto com os comentários a respeito das competências. O primeiro gráfico gerado, representado na Figura 3, é repassado a todos os integrantes da equipe e possibilita uma comparação entre as avaliações do ano em vigor e sua autoavaliação atual. Assim, é possível mensurar o comportamento em períodos distintos e as expectativas do integrante no período em questão.

IX COEN - Congresso de Engenharias da UFSJ Interconexão. 

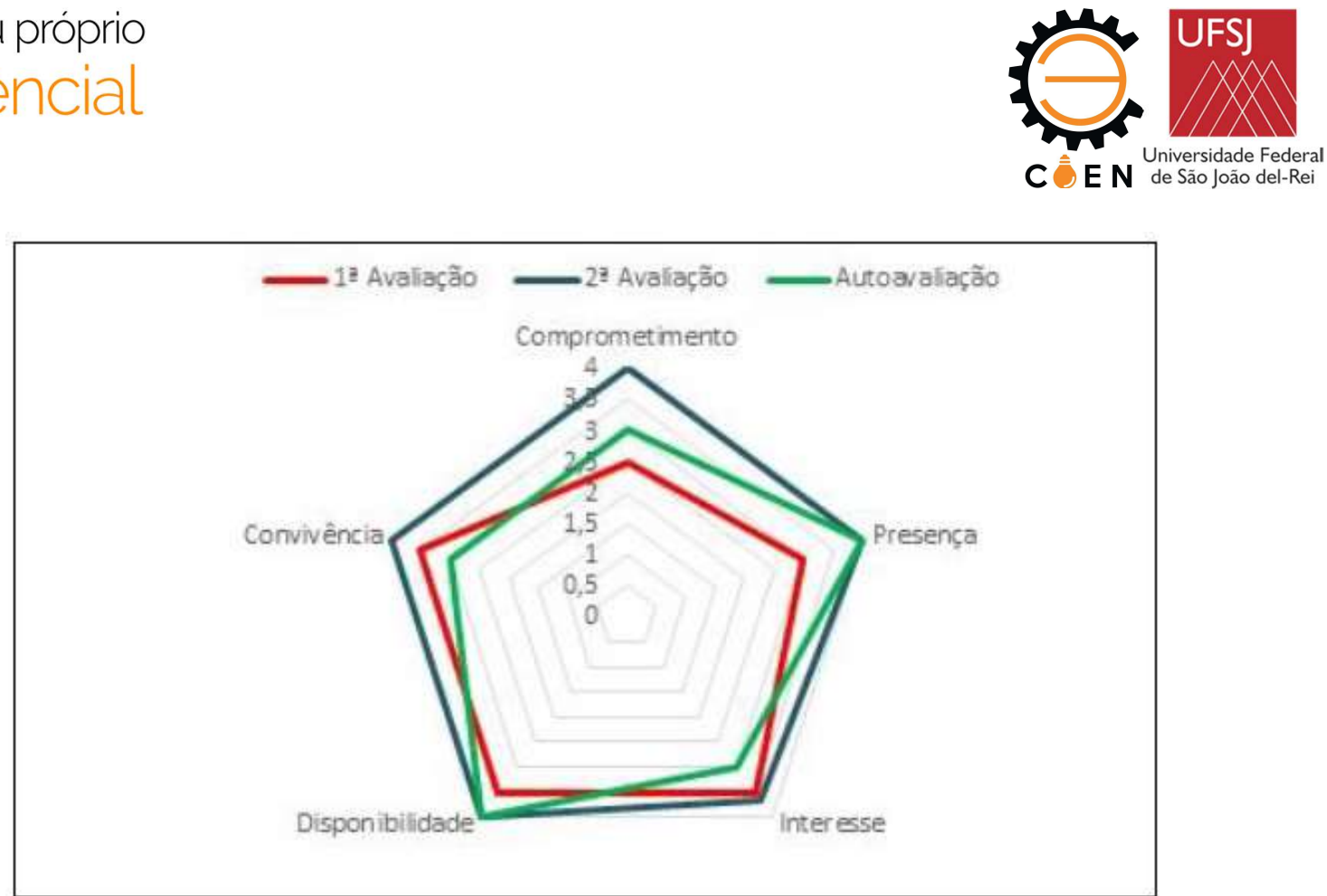

Figura 3. Modelo do primeiro gráfico utilizado na $\mathrm{AD}$ da equipe.

O segundo gráfico (Figura 4), assim como o primeiro, é repassado a todos integrantes da equipe e está relacionado ao comportamento do avaliado perante outros integrantes. Desse modo, é possível dimensionar e comparar sua avaliação com os demais membros da equipe. Nesse gráfico, são levados em consideração a média do setor em que o integrante está alocado, sua média pessoal e a média da equipe como um todo.

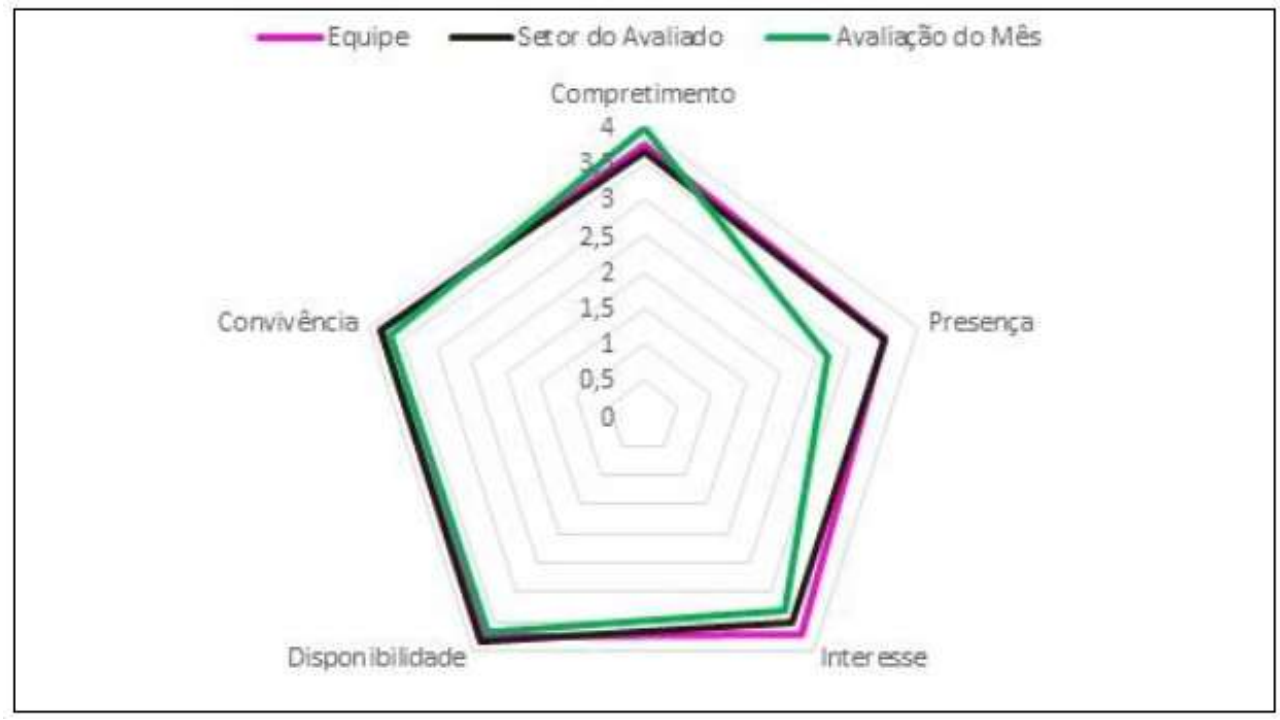

Figura 4. Modelo do segundo gráfico utilizado na $\mathrm{AD}$ da equipe.

O terceiro gráfico gerado é repassado aos coordenadores de área e relaciona-se diretamente com o primeiro e segundo gráficos já demonstrados e exemplificados. Nesse item, há a comparação entre as avaliações do setor em períodos distintos ao longo do ano em relação à avaliação da equipe como um todo. Desse modo, é possível mensurar como está o comportamento de cada setor se 

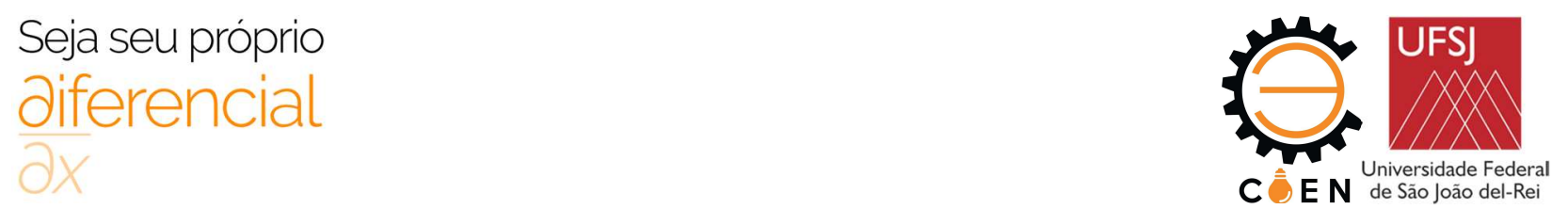

comparado à equipe. O quarto gráfico é repassado para a capitania e este compara o rendimento da equipe como um todo em diferentes períodos do ano. Assim, é possível mensurar o comportamento dos integrantes em cada época.

\section{RESULTADOS E CONCLUSÕES}

Além da valorização de comportamentos positivos, há com o feedback o reconhecimento dos pontos falhos do avaliado que necessitam de melhorias. Através disso, gera-se a motivação desejada ao integrante que tende a corrigir os pontos negativos e intensificar os pontos exaltados. Além disso, através dos gráficos há a conscientização e possibilidade de retroação ao avaliado que gera no próprio membro a vontade de evoluir se comparado às últimas avaliações, tanto individuais quanto coletivas, com intuito de superação.

Nesse sentido, ao analisar os resultados, quando comparadas às avaliações do ano de 2018 dos integrantes da equipe, em $80 \%$ dos casos houve um aumento significativo de pelo menos três das competências avaliadas, isto é, quando comparada à primeira e última avaliação no ano decorrido, houve um crescimento igual ou superior a 0,4 pontos na média individual. Em relação à avaliação dos setores, em nenhum dos dez existentes na equipe foi notado ponto de queda nas competências se comparada à primeira e última avaliação. Além disso, quando analisadas as avaliações do último ano, nota-se que $72 \%$ dos integrantes tornaram-se mais críticos em pelo menos três das competências avaliadas. Isto é, $72 \%$ dos avaliados reduziram sua autoavaliação enquanto sua média do setor aumentou no mesmo período. Em relação à média geral da equipe, foi possível identificar crescimento em todas as competências nas quatro avaliações do ano de 2018, com crescimento gradativo ao longo do ano (Figura $5)$.

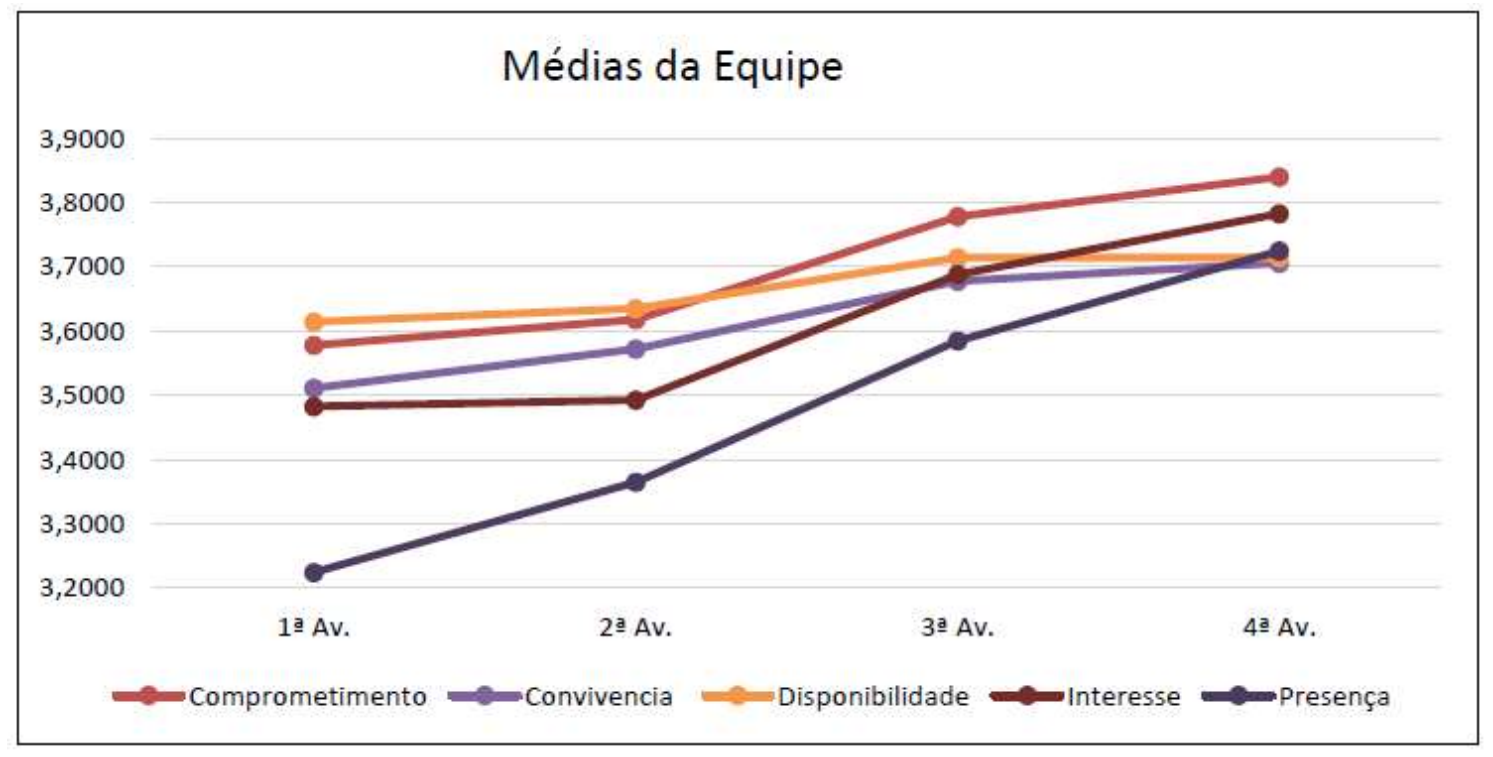

Figura 5. Gráfico comparativo da Equipe ao longo do ano de 2018.

Através do procedimento torna-se possível o dimensionamento do rendimento da equipe em relação às épocas do ano de forma a interferir na definição de cronogramas. Além disso, com o aumento de rendimento dos integrantes, a evolução dos setores tornou-se significativa. 


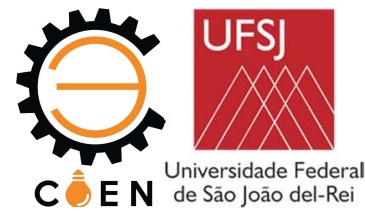

De acordo com o crescimento das competências de comprometimento e disponibilidade, as atividades passaram a ser cumpridas com excelência e no prazo estabelecido, fator que garante não só o estabelecimento do cronograma, mas também a melhoria do projeto e a resolução de objetivos. Além disso, com a melhora nas competências de convivência e presença foi possível garantir a minimização de falhas decorrentes à falta de comunicação, além da redução de brigas e malentendidos dentro do ambiente de trabalho. A evolução dessas competências é crucial para o clima organizacional da equipe e a troca mútua de conhecimentos. A evolução da competência de interesse é preponderante para a evolução da equipe, visto que, através dela, os integrantes buscam inovações e alternativas para o projeto de forma a desenvolver cada vez mais o protótipo.

Tais alterações, além de gerar benefícios para equipe com menos falhas de projeto e membros mais capacitados, acarretam diversas alterações na vida profissional e acadêmica do avaliado, visto que, como citado anteriormente, estão relacionadas ao crescimento da motivação e autoconhecimento do indivíduo. Sendo assim, em virtude disso, desde o início da aplicação da Avaliação de Desempenho na equipe é notada gradativa alteração no tempo de permanência dos membros como integrantes efetivos da equipe. Nessa linha, com o aumento do tempo de permanência, capacitação e identificação do integrante com a equipe, a colocação nacional da equipe evoluiu desde o início da aplicação da Avaliação de Desempenho, no ano de 2017, como representado no gráfico a seguir (Figura 6):

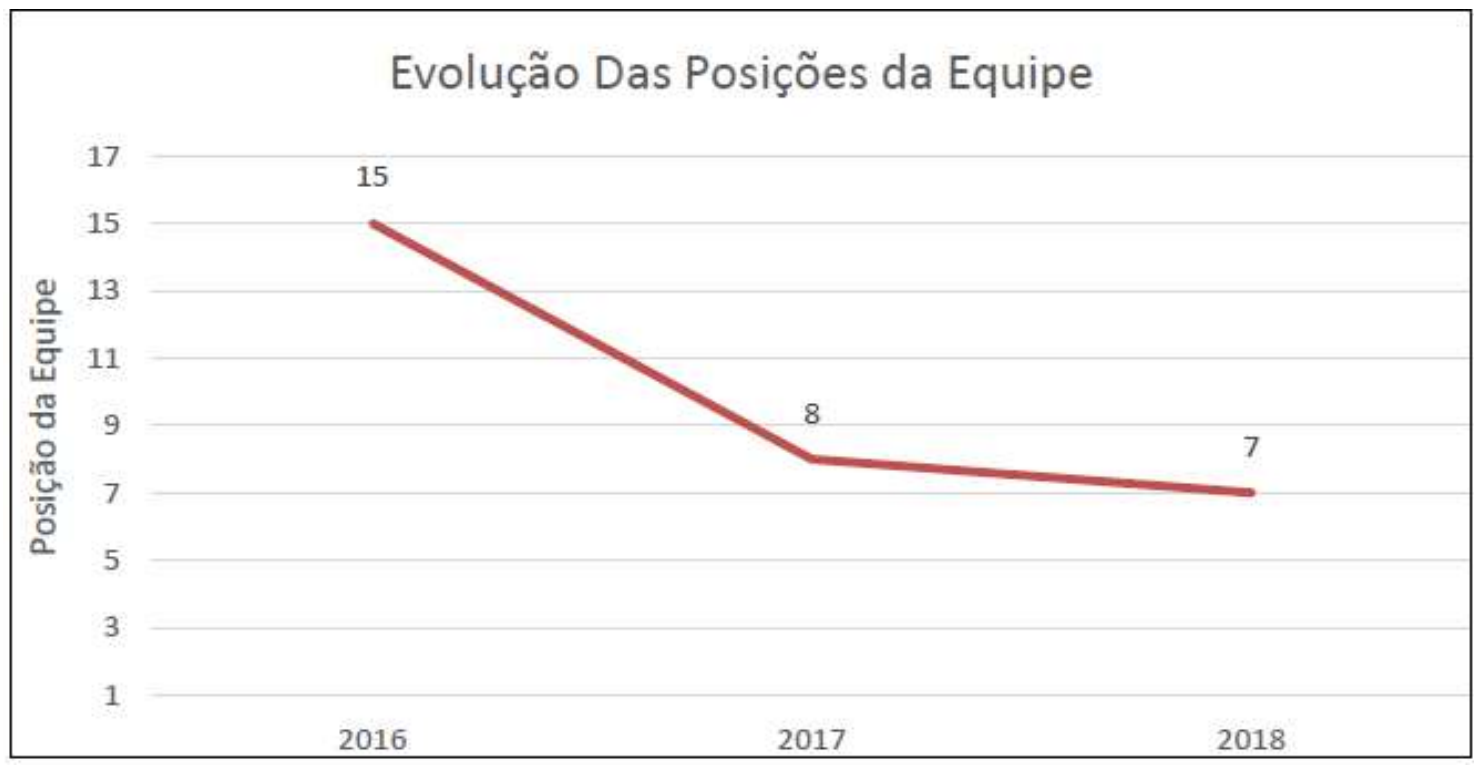

Figura 6. Gráfico de evolução da Equipe ao longo dos anos.

Portanto, no cenário atual, a sociedade tem se tornado um âmbito onde a geração de informações e mudanças ocorrem em uma velocidade cada vez maior, e diante disso, a globalização tem sido considerada uma das principais razões para que as instituições busquem, constantemente, o equilíbrio entre o trabalho e o desenvolvimento dos colaboradores para que consigam sobreviver às transformações que ocorrem no moderno mundo competitivo.

Diante disso, este trabalho procurou evidenciar como a Avaliação de Desempenho $360^{\circ}$, aplicada na equipe Fórmula Del-Racing UFSJ, tornou-se uma ferramenta de grande importância para que os objetivos organizacionais fossem atingidos. Dessa maneira, a Avaliação de Desempenho 

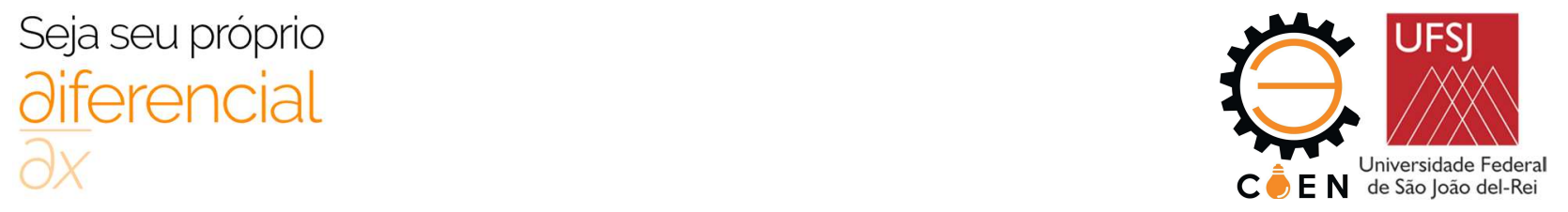

instaurada na equipe em agosto de 2017 tem cumprido seu objetivo de possibilitar o aperfeiçoamento de desempenho, motivação e comunicação dos integrantes, além das demais competências e níveis de desenvolvimento profissional.

\section{AGRADECIMENTOS}

Agradecemos, primeiramente a Deus que nos permitiu que tudo isso acontecesse e fosse possível. A esta Universidade, seu corpo docente, direção e administração que oportunizaram este congresso. Agradecemos, também, a Equipe Fórmula Del-Racing UFSJ e seus membros por proporcionar o conhecimento, orientação, apoio e confiança em todos os momentos. Por fim, a todos que de forma direta ou indireta fizeram parte disso, o nosso muito obrigado.

\section{DIREITOS AUTORAIS}

Os autores são os únicos responsáveis pelo conteúdo das informações contidas neste artigo.

\section{REFERÊNCIAS}

BARBOSA, R. D. S., ESTENDER, A. C. A Gestão Estratégica de Pessoas -uma Ferramenta Necessária a Toda Companhia. In: SIMPÓSIO DEEXCELÊNCIA E GESTÃO EM TECNOLOGIA, 11., 2014. Rio de Janeiro: AEDB, 2014. Disponível em: $<$ http://www.aedb.br/seget/arquivos/artigos14/18720144.pdf $>$. Acesso em: abril de 2019.

BORSATTO, S. Avaliação de Desempenho na UFRGS: os lugares e o sentido de um modelo de gestão. 2012. 83 f. Monografia (Especialização em Gestão Pública) - Universidade Federal do Rio Grande do Sul. Porto Alegre. 2012. Disponível em: $<$ http://www.lume.ufrgs.br/bitstream/handle/10183/71510/000876108.pdf?sequence=1 $>$. Acesso em: 27 abr. 2019.

BOWDITCH, J. L; BUONO, A. F. Elementos de Comportamento Organizacional. São Paulo: Pioneira, 2002.

BRANDÃO, H. P. et al. Gestão de desempenho por competências integrando a gestão por competências, o balanced scorecard e a avaliação 360 graus. Revista de Administração Pública, Rio de Janeiro, Out. vol. 42, n. 5, p. 875-898, set./out., 2008.

CHIAVENATO, Idalberto. Gestão de pessoas: Um novo papel dos recursos humanos nas organizações. 4. ed. São Paulo: Manole, 2014.

GODOY, C. M. B. de. Gestão de Desempenho por competências no Banco do Brasil: a opinião dos funcionários de Santa Catarina sobre o processo. Itajaí-SC, 2007.

LAMPERTI, Maridiani; DEWES, Fernando. A avaliação de desempenho humano: uma análise comparativa entre teoria e práxis em empresa do ramo metalúrgico. Revista de Administração de Empresas Eletrônica-RAEE, n. 4, 2016. Disponível em: <https://seer.faccat.br/index.php/ administracao/article/view/397> Acesso em: 15/04/2019.

MATOS, F. L. F. Desenvolvimento de um Sistema de Avaliação de Desempenho: um estudo de caso. 2012. 109 f. Projeto (Mestrado Gestão de Recurso Humano) - Universidade do Minho. Disponível

IX COEN - Congresso de Engenharias da UFSJ Interconexão. 


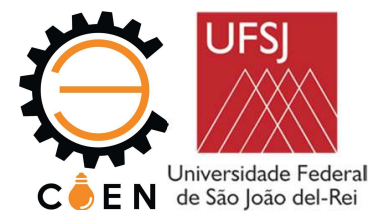

em: $\quad<$ http://repositorium.sdum.uminho.pt/bitstream/1822/19790/1/Florbela\%20Leite\%20Ferreira \%20Matos.pdf $>$. Acesso em: 26 mar. 2019.

MONTEIRO, S. et. al. Gestão de pessoas: a valorização do humano como um diferencial para o êxito de uma organização. MOTTA, Carolina da Cruz. Avaliação de desempenho. 2015.

SEBRAE, Serviço Brasileiro de Apoio às Micro e Pequenas Empresas. Avaliação de desempenho como forma de reconhecimento ao funcionário. Disponível em: $<\mathrm{http}: / / \mathrm{www}$.sebrae.com.br/sites /PortalSebrae/bis/Funcion\%C3\%A1rio-com-bomdesempenho-eve-ser-reconhecido $>$ Acesso em: 17 de maio de 2019.

SEGATTO-MENDES, Andréa Paula; MENDES, Nathan. Cooperação tecnológica universidadeempresa para eficiência energética: um estudo de caso. Revista de Administração Contemporânea, 2018, 10.spe: 53-75.

\section{PERFORMANCE EVALUATION APPLIED TO A FORMULA SAE TEAM}

Carla Fabiana Silva Nery ${ }^{(1)}$ (carlafsnery@gmail.com), Lucas Apolonio de Almeida Martins ${ }^{(1)}$ (lucas_apolonio1322@hotmail.com), Victor Thomaz da Cunha Aragão ${ }^{(1)}$ (victoraragao67@gmail.com)

(1) Universidade Federal de São João del-Rei (UFSJ) - Praça Frei Orlando, 170, Centro, São João del-Rei, Minas Gerais

ABSTRACT: In a world highly globalized as the current one, people are considered at every moment more preponderant factors for the success of organizations, Because they are the people who strengthen the imagination, creativity, innovation and dynamics of the institutions. Because of this, people management and human performance assessment has become increasingly present in companies. Therefore, the area seeks the development, retention and motivation of the worker for the performance of their functions and tasks. In this sense, the article in question seeks to analyze how the performance assessment, area of people management Is practiced in the formula Del Racing UFSJ team, and as the are acorroborates the maintenance of the Members, Aligned with the increase of motivation and qualification of the members, besides demonstrating the growing evolution of the team in the national scenario. Thus, through the case study in the formula SAE team of the city of São João Del-Rei-MG, it was possible to verify and analyze the evaluation $360^{\circ}$ That through five related competencies in numerical and textual scales, Develops graphics and feedbacks in an integrated system across all sectors and members of the organization. With the general aim of demonstrating the importance of this issue to the corporation and how the application of this tool has contributed Since its implementation in the development of the team, thearticle goes through fundamental points both of the history and theoretical basis of the evaluation of performance and people management, such as the relationship of the member in the student and professional sphere.

KEYWORDS: People management, performance assessment, evaluation $360^{\circ}$, feedback, formula 